\title{
Hydroxyurea Regimen
}

National Cancer Institute

\section{Source}

National Cancer Institute. Hydroxyurea Regimen. NCI Thesaurus. Code C160050.

A chemotherapy regimen consisting of hydroxyurea that may be used in the treatment of myeloproliferative neoplasms, including acute myeloid leukemia (AML). 